\title{
Opioid receptors: distinct roles in mood disorders
}

\author{
Pierre-Eric Lutz and Brigitte L. Kieffer \\ Institut de Génétique et de Biologie Moléculaire et Cellulaire, Centre National de Recherche \\ Scientifique (CNRS)/ Institut National de la Santé et de la Recherche Médicale(INSERM)/ \\ Université de Strasbourg, Illkirch-Graffenstaden, France.
}

\begin{abstract}
The roles of opioid receptors in pain and addiction have been extensively studied, but their function in mood disorders has received less attention. Accumulating evidence from animal research reveal that mu, delta and kappa opioid receptors (MORs, DORs and KORs, respectively) exert highly distinct controls over mood-related processes. DOR agonists and KOR antagonists have promising antidepressant potential, whereas the risk-benefit ratio of currently available MOR agonists as antidepressants remain difficult to evaluate, in addition to their inherent abuse liability. At present, both human and animal studies have mainly examined MORs in the etiology of depressive disorders, and future studies will address delta and kappa receptor function in established and emerging neurobiological aspects of depression, including neurogenesis, neurodevelopment and social behaviors.
\end{abstract}

\section{Keywords}

mu opioid receptor; delta opioid receptor; kappa opioid receptor; mood; depression

\section{Introduction}

Endogenous opioids and their receptors were discovered from the early use of opium in both medicinal and recreational practices. Morphine, the most active ingredient of opium, has highly potent pain-relieving properties and remains the most widely used painkiller in modern medicine, despite a plethora of undesirable effects. Among these, abuse liability remains a limitation when undertaking opioid-based pain therapies. Heroin - the diacetylated morphine derivative - has even stronger addictive properties and, as a major illicit drug of abuse, represents a public health problem worldwide.

Opiate drugs hijack a complex neuromodulatory system composed of three receptors, mu, delta and kappa, which interact with a family of endogenous opioid peptides known as $\beta$ endorphin, enkephalins and dynorphins. Opioid receptors form a subfamily of G-protein coupled receptors (GPCRs), which also includes the homologous but non-opioid nociceptin/ orphanin FQ receptor. Both receptors and peptides are expressed throughout peripheral and central nervous systems [1], and have been the subject of intense investigations for several decades. Opioids play a central role in pain processing and regulate many other aspects of

(C) 2012 Elsevier Ltd. All rights reserved.

Corresponding author: Kieffer B.L. (briki@igbmc.fr).

Publisher's Disclaimer: This is a PDF file of an unedited manuscript that has been accepted for publication. As a service to our customers we are providing this early version of the manuscript. The manuscript will undergo copyediting, typesetting, and review of the resulting proof before it is published in its final citable form. Please note that during the production process errors may be discovered which could affect the content, and all legal disclaimers that apply to the journal pertain. 
physiology that include stress responses, respiration, gastrointestinal transit, as well as endocrine and immune functions [2]. The mood-regulating properties of endogenous opioids represent another main aspect of opioid physiology. The potent euphoric effects of known opiate drugs, and the high density of peptides and receptors in limbic brain areas, set the opioid system as a central player in both reward processing and mood control (see Glossary), and a feasible target to treat emotional dysfunction [3].

Mood disorders are defined as a group of diagnoses where mood disturbance is the main underlying feature. Among these, major depressive disorder (MDD) is a chronic relapsing disorder characterized by the repetition of major depressive episodes (MDE). The natural course of a depressive episode is remission (50\% at one year), even in the absence of medical intervention. Unfortunately, $80 \%$ patients experience relapse within 15 years [4]. Depression is a worldwide leading cause of disability, expected to even worsen in the next decades [5]. In the early 1900's, an opioid cure was proposed for the treatment of depressed patients, through progressive exposure to low doses of an opiate mixture. Although seemingly effective [6], this approach was hampered by the inherent addictive properties of available opiates, as is the case for pain treatment. Since the advent of monoamine targeting drugs in the 50's, the antidepressant utility of opiates was less considered, and first line treatments in modern medicine currently rely on selective serotonin reuptake inhibitors (SSRIs). SSRIs however are effective in only 40-50\% patients [7], and identifying new targets for therapeutic intervention stands as a major challenge.

Today, opioids are re-entering the therapeutic arsenal for MDD treatment. Agonists such as buprenorphine are used in the specific contexts of refractory depression [8] and depressionaddiction comorbidity [9], and may have broader indications. Recent clinical and animal research data further strengthen the notion that endogenous opioids contribute to the etiology of mood disorders. Here we will review both genetic and pharmacological approaches that reveal mu, delta and kappa opioid receptors as highly distinct players in reward processes and emotional responses, and very different targets for clinical intervention in MDD. The role of endogenous opioids has been partly reviewed elsewhere [10], and will only be briefly mentioned when appropriate.

\section{Opioid receptor knockout studies in behavioral models of reward and mood disorders}

Constitutive knockout (KO) mice for MOR, DOR and KOR have been created almost two decades ago [11], and characterized for reward processes and mood states [1, 12, 13], which both involve hedonic responses [14] (Figure 1).

Data from MOR KO mice concur to establish that this receptor represents a key molecular player for reward processing of both natural stimuli and drugs of abuse. This robust activity contributes to recreational drug use and facilitates the onset of addictive behaviors [15]. The strong rewarding effect of MOR agonists likely contributes to the reported success of the 'opioid depression cure' [6]. Besides, two groups reported decreased anxiety- and depressive-like behaviors in MOR KO mice, indicating the possibility of a paradoxical depressant role of MOR in regulating emotional responses [16, 17]. MOR-mediated mechanisms of mood control may therefore be more complex than previously anticipated, a notion that is supported by the pharmacology (see below).

Whether DORs regulate reward processes is less clear [18]. Morphine place preference was decreased in DOR KO mice [19, 20], but morphine self-administration was preserved [20, 21], suggesting that DORs contribute to contextual learning rather than opioid reward. Alcohol drinking was increased [22] whereas nicotine self-administration was decreased 
[23], strengthening the view that DORs regulate reward processes in a complex manner. Importantly, genetic deletion of DORs led to a robust increase in anxiety and depressive-like behaviors [16], a phenotype that was not found in KOR KO mice, and partly recapitulated in preproenkephalin KO mice [24]. Further studies largely confirmed mood-enhancing activity of the enkephalin/DOR system [18]. Intriguingly, high anxiety levels of mutant mice were reduced after alcohol self-administration [22], in favor of the self-medication hypothesis [25].

In addiction research, the dynorphin/KOR is definitely considered a major anti-reward system opposing MOR activity [26]. KO data are consistent with the view that KOR activity tonically decreases reward, although this is not detectable for all drugs of abuse. In addition, it is now well-established that the KOR activity is potentiated by several stressors (eg. social defeat or repeated forced swim, FS), and participates in stress-induced psychopathology [27]. Accordingly, enhanced cocaine seeking triggered by such stressors in wild-type mice is not detectable in mutant mice presumably due to lack of dynorphin/KOR-mediated dysphoric state [28]. Because of the importance of stress in recruiting KORs it is not surprising that, in contrast to DOR KO mice, KOR KO mice did not differ from controls in classical behavioral models of depressive-like behaviors involving limited stress [16].

Altogether, current knowledge clearly indicates that all three opioid receptors differentially regulate reward processes and emotional responses, demonstrating highly distinct mu, delta and kappa opioid receptor-mediated mechanisms for mood control.

\section{Antidepressant potential for MOR, DOR and KOR drugs}

Pharmacological data (Table 1) demonstrate effects of opioid drugs in rodent models of depression. Historically, antidepressant-like effects of enkephalins and endorphins were first reported in the FS in rats [29]. Inhibitors of enkephalinase [30], and the general opioid antagonist naloxone [31], were later found to have antidepressant- and depressant-like effects, respectively, in the learned helplessness model (LH). These results indicated that endogenous opioid peptides regulate despair-like behaviors. Other studies using selective MOR, DOR and KOR drugs confirmed the distinct roles for each opioid receptor, as revealed by genetic approaches.

The antidepressant-like activity of DOR agonists is the most well-documented. Consistent with increased depressive-like behaviors in DOR KO mice (Figure 1), studies have shown that DOR receptor activation by several agonists has antidepressant-like effects across four behavioral paradigms in both rats and mice: LH, FS, tail suspension (TS) and olfactory bulbectomy (see Table 1 and [31-49]).

Similar to DOR, but less documented, acute pharmacological activation of the MOR reduces depressive-like behaviors in some (eg. LH in rat, TS and FS in mice, see [31, 49-53]), but not all [54], studies. Pharmacological antidepressant-like effects of MOR agonists are in apparent contradiction with the decreased depressive-like behaviors observed in MOR KO mice (Figure 1). There are several possibilities to explain this discrepancy. First, constitutive MOR KO mice may have developed a compensatory high mood state. Second, MOR expression may be dynamically regulated during brain development, and MOR-dependent signaling may show both negative and positive effects on mood during development and adulthood, respectively. Third, acute (ie. pharmacological treatment) versus chronic (ie. constitutive KO) MOR activation may have antidepressant versus depressant-like effects, respectively.

Systemic administration of KOR drugs produces mood-altering effects in classical models of depressive-like behaviors. Notably, KOR agonists (eg. U69493) and antagonists (eg. ANTI, 
GNTI, JDTic and nor-BNI) showed depressant and antidepressant-like effects, respectively, in the FS and LH in rats [55-57]. Further, depressant activity of the endogenous dynorphin/ KOR system is now being extensively investigated in other rodent models of depression (notably acute or chronic social defeat, as discussed below).

In summary, DOR agonists and KOR antagonists have promising antidepressant potential, and both DOR and KOR drugs are under development. In contrast, data from MOR analysis appear more complex.

\section{Opioid receptors and the neurobiology of depression}

Many neurotransmitter systems and brain sites are involved in the pathogenesis of depression [58] and opioid receptors regulate a number of these aspects (see Figure 2A and 2B). Relevant to depression, opioid receptors also regulate activity of the hypothalamuspituitary-adrenal gland (HPA) axis, a major endocrine stress system. This aspect of opioid receptor function, and implications for mood, has been reviewed elsewhere [27, 59].

\section{Monoaminergic systems}

The dopaminergic (DA) mesolimbic system regulates hedonic homeostasis and, as such, contributes to mood disorders [60]. At the cellular level, KOR have been located on presynaptic terminals of DA neurons in the NAc (see Figure 3 and [61]). Local overexpression of the transcription factor, cAMP response element-binding protein (CREB), in the NAc increased both dynorphin/KOR signaling and depressive-like behaviors [27], directly correlating KOR-mediated inhibition of DA release to lowered mood. Similarly, local infusion of nor-BNI (ie. a KOR antagonist) within the NAc mimicked the antidepressant-like effect of systemic KOR blockade using the LH paradigm in rats [57, 62]. Enkephalin release in DA pathways is also involved. The encounter of an unfamiliar congener triggers detectable release of the opioid peptide in the rat NAc [63], an effect that may mediate social reward, at least in part. Further, this enkephalin release was lost in anhedonic chronically stressed rats [63], suggesting that a low enkephalin tone in the NAc associates with stress-induced anhedonia. Chronic treatment with amilsulpiride, a dopamine D2 receptor antagonist, potentiated antidepressant-like effects of DOR activation [64], suggesting antagonistic functions of D2 and DOR in mood control. Finally, in addiction research, a large body of work has documented the activation of DA neurons by MOR activation in the ventral tegmental area (VTA) [15]. Data also indicate that activation of MOR and DOR receptors regulate DA release in the NAc, with distinct effects across various sub-nuclei of the NAc [65]. Although much is known about the complex DA/opioid interaction in addictive behaviors, additional studies are required to understand functional interaction of MOR, DOR and DA systems in animal models of mood disorders.

The monoamine theory of depression posits that decreased activity of either serotonergic (5HT) or noradrenergic (NA) neurons underlies depressive disorders [58]. Pharmacological studies show that the combination of sub-effective doses of codeine, a weak MOR agonist, with a SSRI is behaviorally effective in the TS test [51] and that effects of two tricyclic antidepressants in the FS are antagonized by the general opioid antagonist naloxone [66], establishing interactions between 5-HT/NA and opioid systems.

MORs tightly control the activity of 5-HT neurons. Systemic acute morphine injection increases 5-HT release in various limbic regions in rats [67] and mice [68], an effect antagonized or mimicked by infusion into the dorsal raphe nucleus (DRN) of a MOR antagonist [69] or agonist [67] respectively. MORs in the median raphe nucleus (MRN) do not control 5-HT neurons, as morphine infusion in the MRN had no effect on local or forebrain 5-HT release [67]. Similar to DA neurons (Figure 3), morphine is proposed to 
activate 5-HT neurons through a disinhibition mechanism, with local GABAergic interneurons in the DRN expressing MORs [69]. Chronic morphine had opposing effects and led to a compensatory up-regulation of the GABAergic tone on 5-HT neurons, resulting in decreased 5-HT activity upon cessation of chronic treatment and during withdrawal [70].

Long-term effects of chronic morphine on mood have only been investigated recently in rodents. Depressive-like behaviors were detectable in acute withdrawal from chronic morphine treatment in rat [71, 72], and after more prolonged withdrawal, or abstinence, in rat [73] and mouse [74, 75]. The latter mouse study showed that behavioral deficits progressively strengthen during 4 weeks of abstinence [75]. Importantly, these emotional deficits were prevented by chronic SSRI-treatment during the withdrawal period. In this model, chronic morphine induced sequential signaling adaptations at the level of the $5-\mathrm{HT}_{1 \mathrm{~A}}$ receptor [76] - the main autoreceptor controlling 5-HT neurons activity - which transiently desensitized during morphine abstinence. This molecular adaptation was previously identified in several rodent models of depression [77]. Finally, mice lacking most central 5HT neurons [78] showed normal morphine conditioned place preference (CPP), suggesting an interesting anatomical dissociation between MOR-mediated mechanisms underlying the regulation of reward processes and affective states. 5-HT neurons activity is also regulated by DOR and KOR [79], and the latter has received much attention. Rescue experiments showed that KOR expression in 5-HT neurons innervating the NAc, on a KOR KO background, is sufficient to restore KOR agonist-induced place aversion [80]. This finding suggests that dysphoric activity of the KOR may engage 5-HT-mediated modulation of the DA system in the NAc. Furthermore, acute social defeat triggered phosphorylation of KOR and p38a kinase in the DRN [81]. Phosphorylated p38a in turn promoted serotonin transporter (SERT) translocation to the plasma membrane, thereby increasing 5-HT reuptake, a mechanism likely responsible for defeat-induced acute social avoidance. Whether KOR/p38a signaling in the DRN is also involved in prolonged mood-related deficits has yet to be determined.

Finally, NA neurons are also sensitive to endogenous opioidergic modulation. In contrast with 5-HT and DA neurons, NA neurons express the MOR. Thus, acute morphine injection increased 5-HT and DA release, but decreased NA release in the forebrain [82]. Following chronic opiate treatment, rebound from this inhibitory effect produced hyperactivity of the NA system. In particular, hyperactivity of NA neurons targeting the Bed Nucleus of the Stria Terminalis (BNST) was shown to mediate place aversion induced by acute precipitated opiate withdrawal [83], and may also be implicated in altered rewarding properties of natural stimuli (eg. food) during abstinence from opiates [84]. To our knowledge, there is no report on the long-term consequences of MOR-mediated adaptations in the NA system on emotional responses.

\section{Neurogenesis \& cell fate specification}

In the hippocampus, synaptic plasticity and neurogenesis (in the sub-granular zone of the dentate gyrus) are implicated in both depression pathogenesis and effects of antidepressants [85, 86], and MOR modulates both aspects.

Life stress events decrease neurogenesis and decrease dendritic length, dendritic arborization or spine density, while antidepressants reverse these effects $[85,86]$. Chronic morphine selfadministration has been shown to decrease dendritic spine density in hippocampal CA1 region and in the dentate gyrus up to one month after termination of drug consumption [87]. Also, numerous findings have shown that chronic (but not acute) treatment with morphine leads to decreased neuronal proliferation and survival in the hippocampus of adult rats \& mice, independently of their effects on the HPA axis [88]. Conversely, MOR KO mice exhibited increased neuronal survival [89] and cellular proliferation [90]. Together these 
results suggest that sustained MOR signaling decreases structural plasticity and neurogenesis in the hippocampus.

Throughout life, radial astrocyte-like neural stem cells (NSC) undergo mitotic divisions to sustain self-renewal and generate new neurons in the hippocampus. While the ratio between NSC and neuronal progeny is controlled by neuronal activity and life experiences [91], in vivo and in vitro evidence suggest that MOR and DOR may be implicated in both aspects. In vivo, chronic morphine treatment increased immunoreactivity for glial fibrillary acidic protein (GFAP, a marker of mature astrocytes and NSC) in the hippocampus [92]. In vitro, chronic treatment of adult hippocampal progenitors with specific MOR (ie. $\beta$ funaltrexamine) and DOR (ie. naltrindole) antagonists decreased their differentiation into both astrocytes and oligodendrocytes, while favoring neuronal fate [93]. By contrast, the KOR antagonist nor-BNI had no effect. Interestingly, a recent report [91] showed that social isolation - a major risk factor for depression - favors NSC over neuronal cell fate. It is therefore possible that the opioid system, known to mediate social stimuli and to be involved in social isolation (as discussed below), contributes to mood disruption via dysregulation of hippocampal cell fate specification.

Brain derived neurotrophic factor (BDNF) is one of the most studied molecular substrates known to have important roles in hippocampal synaptic adaptations and neurogenesis. BDNF promotes proper spine density in the hippocampus, mediates antidepressant responses and regulates depressive-like behaviors [94]. Interestingly, opioid receptors regulate BDNF activity. Systemic administration of peptidic [47] and non-peptidic [95] DOR agonists, as well as of the KOR antagonist nor-BNI [96], showed antidepressant-like effects in rats and increased BDNF mRNA in the hippocampus, as well as other structures (eg. frontal cortex, amygdala, hippocampus, endopiriform cortex). Also, endogenous opioids (ie. enkephalins) up-regulated BDNF mRNA in the hippocampus in a naltrindole (ie. DOR) and naltrexone (ie. a MOR-specific dose) reversible manner [54], suggesting that all 3 opioid receptors control expression of this major neurotrophic factor. Altogether, results indicate that opioids have potentially beneficial (ie. increased BDNF) and detrimental (ie. reduced synaptic density \& neurogenesis) effects on hippocampal mood substrates, yet their combined behavioral relevance remains to be determined.

\section{Neurodevelopmental influences}

Depression is often associated with adverse developmental conditions. During brain maturation, genetic and environmental factors shape emotional circuits to establish personality and affective traits [97, 98]. In rats - similar to morphine exposure in adulthood in utero treatment impaired hippocampal structure [99], an adaptation that may contribute to the development of depressive-like behaviors in adulthood. Indeed, perinatal morphine exposure increased depressive-like behaviors at early adolescent and adult ages [100]. In humans, activation of opioid receptors during fetal brain development may also have lifelong consequences. Children from mothers that were dependent on opiates during gestation exhibited significantly elevated anxiety, aggressivity and peer rejection [101], although the respective contributions of environmental factors and in utero heroin exposure are debated [102].

\section{Social life}

Social hedonic capacity is a major determinant of emotional well-being in humans [103], and social stressors provide preclinical research with ethologically relevant models of depression [58]. In particular, social isolation was shown to activate brain circuits partly overlapping with nociceptive circuits in several species [104], and such "social pain" [105] is attenuated through stimulation of MORs [106]. Along these lines, activation of MORs in 
adolescent mice was found to decrease social isolation-induced exploration of a familiar congener [107]. In addition to social isolation, chronic social defeat (CSD) is a social stressor known to induce anhedonia and depressive-like behaviors. Surprisingly, social avoidance induced by CSD was attenuated in MOR KO mice [108]. Together, these results suggest that an endogenous opioid tone targeting MORs is regulated as a function of social stimuli, and that both a decrease (eg. via social isolation) or an increase (eg. via social defeat) of this opioid tone has detrimental consequences on mood, possibly through differential neuronal mechanisms. Similarly in humans, the best studied MOR gene variant A118G (whose functional relevance is debated [109]), is associated with increased social hedonic capacity [110] but greater reactivity to social rejection [111]. KORs also regulate social behaviors and associated depressive-like behaviors. The KOR antagonist nor-BNI partly prevented defeated postures induced by social stress [112] in the rat, and KOR signaling within the NAc was shown to mediate rejection of social conspecifics, thus maintaining pair bonds in the monogamous prairie vole [113].

Social behaviors show a well-recognized developmental pattern, and MORs contribute at early stages. Male rats exposed to morphine in utero exhibited increased pinning (a measure of play behavior) and social grooming [114] at juvenile age, in addition to increased sociability and decreased social avoidance at adult age [115], indicating that early opiate exposure may have life-long stimulating effects on social behaviors. Bowlby's attachment theory posits that infants need to develop an intimate, continuous relationship with a primary caregiver so that social and emotional behaviors develop normally [116]. Maternal separation - a developmental variant of social isolation - induces distress calls that were strongly reduced in MOR KO mice pups [117] and required MOR activation in infant primates [118]. Thus, expression of MORs is essential for the establishment of maternal attachment, and exogenous MOR activation attenuates the expression of maternal separation-induced stress response. Also, MOR gene variants correlate with the quality of parental attachment in infant primates (eg. C77G, [119]) and humans (eg. A118G, [120]).

Conversely, several reports indicate that the quality of maternal care has long-term effects on the opioid system. Maternally separated rats showed increased physical signs of morphine withdrawal [121] and decreased sensitivity to morphine anti-nociceptive effects [122] that correlated with changes in MOR binding in pain-related brain structures [123]. Thus, adaptations of MOR signaling as a function of maternal care - a crucial determinant of stress responses and stress-related disorders throughout life [124] - may have life-long implications for mood regulation. While attachment-based therapies for depression are currently being investigated [125], a better understanding of opioidergic controls over affiliative behaviors during development and in adulthood may have therapeutic implications.

Later in life, social interactions with peers fulfill an important adaptive role during adolescence [126], promoting encounters with individuals outside the natal group and independence from this group. Social play acts as a natural reinforcer that induces place preference in adolescent rats and mice [127, 128]. Endogenous opioid peptide release was detected throughout the brain during social behaviors in adolescent rodents [129] and MOR and KOR agonists increased and decreased social play, respectively [130]. Considering that the setting of proper social and affiliative behaviors during development and throughout life [103] has crucial adaptive value for affective regulation, it is very likely that opioidmediated regulation of social behaviors has life-long impact on vulnerability to depression. 


\section{Opioid receptors and depression in humans}

\section{Addiction-depression comorbidity}

Comorbidity is extremely frequent in psychiatry, and the association between depression and addiction is one of the most classical clusters [131]. According to the self-medication hypothesis, depressed patients may take advantage of acute euphoric properties of drugs of abuse to overcome their depressed mood, a transient relief that bears its own risk of entering into dependence [25]. Conversely, repeated exposure to drugs of abuse triggers neuroadaptations in brain structures that contribute to mood homeostasis (such as the mesolimbic DA pathway), potentially leading to depressive disorders (substance-induced depressive disorder). Numerous data now convincingly document both hypotheses [132], and the relationship between addiction and depression is undoubtedly bidirectional. As discussed in this review, the opioid system is a central player in both disorders, and thus, a likely major contributor to comorbidity. While acute MOR activation has euphoric and antidepressant-like effects in rodents [3, 49-51], chronic MOR signaling appears as a major risk factor for depression: these properties align well with the self-medication hypothesis and substance-induced depressive disorders, respectively [71-75]. Interestingly, opiate addicts under opiate maintenance therapy still present a high risk of major depressive disorder [133], suggesting that allostatic changes may have developed beyond MORs. Thus, combining MOR agonism (for maintenance therapy) with either KOR antagonism or DOR agonism seems particularly suited to treat patients suffering from both opiate dependence and depression. Encouraging clinical results have been reported for buprenorphine [9], which have been attributed to KOR antagonism, although this opiate shows a complex pharmacology, possibly involving all 3 opioid receptors and the nociception/orphanin FQ receptor [134].

\section{Insights into the human disorder}

Post-mortem autoradiographic studies have examined MOR binding in suicide victims who were mainly diagnosed with depression. MOR expression was increased in frontal and temporal cortex [135-137], as well as in caudate nuclei [136] (compared with controls who died of sudden death but with no history of psychiatric disorder), suggesting that depression and suicide associate with higher MOR density.

Advances in functional neuroimaging have enabled the study of MOR in patients experiencing various mood states. Positron emission tomography (PET) with the MOR selective radiotracer $\left[{ }^{11} \mathrm{C}\right]$-carfentanil was used in healthy women during neutral and sadness states [138]. Compared to the neutral state, the sadness state was characterized by increased binding potential (BP) for the radiotracer, interpreted as a decrease in MOR neurotransmission, in the rostral anterior cingulate, ventral pallidum, amygdala, and inferior temporal cortex. In the future, development of PET ligands with DOR and KOR selectivity should allow similar studies for these two other opioid receptors (for example, see http:// clinicaltrials.gov/ct2/show/NCT00939887?term=kappa\&rank=2).

A similar approach was applied to women diagnosed with MDD [139]. During the neutral state differences were already detectable, with depressed patients showing decreased MOR $\mathrm{BP}$ in the posterior thalamus compared to healthy controls. Together these data suggest that acute (ie. the sadness state in healthy women) and chronic (ie. MDD) negative emotional states associate with opposing activities of MOR, reminiscent of rodent data comparing acute pharmacological stimulation versus constitutive genetic ablation of MORs. Further, the later study [139] showed increased MOR BP in the rostral anterior cingulate in healthy controls under sadness condition but not in depressed patients, and decreased MOR BP in the left inferior temporal cortex of depressed women, highlighting the importance of 
circuitry analysis in comparing emotional reactivity across physiological and pathological conditions.

\section{Concluding remarks}

As behavioral models in rodents get more sophisticated, and neurobiological mechanisms of mood disorders better understood, MOR, DOR and KOR appear as important and highly distinct players in the regulation of emotional states. In brief, animal studies show that DOR improves mood states acutely, KOR decreases mood after stress, and MOR exerts contrasting effects on mood. Clinical trials are needed to evaluate potential benefits of DOR agonist and KOR antagonist strategies to treat depressive disorders. The risk-benefit balance of currently available MOR as antidepressants remains otherwise difficult to evaluate, partly due to their inherent abuse liability. Ongoing studies investigating biased agonism in animal models may reveal antidepressant-like efficacy independent from abuse liability at the MOR opioid receptor, and open the way for novel clinical applications (Box1). Finally, research on causal factors underlying mood disorders has mainly implicated MOR receptors in the etiology of depressive states. Future studies will address the yet unknown roles of DOR and KOR in neurobiological aspects of MDD related to neurogenesis, neurodevelopment and social behaviors.

\section{Acknowledgments}

The authors would like to thank Sandra Bour for her help with figure preparations and Claire Gaveriaux-Ruff for critical reading of the manuscript. This work was supported by the CNRS, INSERM and Université de Strasbourg. We also thank the Mouse Clinical Institute (ICS, Illkirch France), the European Union (Grant No.GENADDICT/ FP6 005166), the Fondation pour la Recherche Médicale (P.E.L.), the Fondation Fyssen (P.E.L.), and the National Institutes of Health (National Institute of Drug Addiction, grant \#05010 and National Institute on Alcohol Abuse and Alcoholism, grant \#16658) for financial support.

\section{Glossary}

Anhedonia

Biased agonism

Chronic mild stress (CMS)

Chronic social defeat (CSD)

\section{Conditioned suppression of motility (CSM)}

Conditioned place preference/ a reward-related deficit characterized by markedly diminished interest or pleasure in all, or almost all, activities.

a now-well recognized phenomenon, whereby GPCRs exist under distinct agonist-dependent active conformations, which form specific agonist/receptor/effector complexes that, in turn, engage distinct and agonist-specific downstream signaling and regulatory responses.

animals are subjected to a variety of unpredictable physical and social stressors, leading to anhedonia and despair-like behaviors.

when exposed to resident aggressive congeners, rodents adopt a submissive characteristic posture. Repeated social defeat episodes produce long-lasting social avoidance and anhedonia.

a close variant of learned helplessness, except the animal cannot avoid footshocks.

a pavlovian conditioning in which a drug is repeatedly paired with a set of environmental stimuli that progressively acquire motivational properties. The animal subsequently exhibits either preference or avoidance upon re-exposure to the environmental 


\section{aversion (CPP/ \\ CPA)}

Forced swim (FS)

\author{
Learned \\ helplessness (LH) \\ Mood
}

Mood disorders

Major depressive episode (MDE)

\section{Maternal separation}

Reward

Reinforcement

Social Interactions

Sucrose preference

Stress

Tail suspension stimuli, a behaviour dependent on learning, motivational, and hedonic mechanisms.

rodents, placed in an inescapable container of water, adopt a floating, immobile behavior interpreted as despair.

animals exposed to inescapable shocks subsequently fail to escape when able to.

a pervasive and sustained subjective emotional state that influences one's whole perception of the world, with generally either a positive (mania) or negative (depression) valence; while an emotion tends to have a clear focus, mood tends to be diffuse.

a group of four diagnoses where mood disturbance is the main feature: (i) major depressive disorder (MDD), the repetition of major depressive episodes (MDE); (ii) dysthymic disorder, a longlasting (2 years or more), less severe form of depression; (iii) bipolar disorder, alternation of manic and depressive episodes; (iv) cyclothymia, a milder form of bipolar disorder.

defined by the presence of 5 (or more) symptoms during a twoweek period (with at least one of the first 2 symptoms) among: depressed mood, anhedonia, weight loss or gain, insomnia or hypersomnia, psychomotor agitation or retardation, fatigue or loss of energy, feelings of worthlessness or excessive or inappropriate guilt, diminished ability to think or concentrate, indecisiveness, recurrent thoughts of death, recurrent suicidal ideation or suicide attempt.

animals separated from their mother during early postnatal life develop depressive-like behaviors.

a stimulus that the brain interprets as intrinsically positive or as something to be approached.

a process that acutely reinforces behaviour, corresponding to the positive value ascribed to natural (eating, mating, social behaviours) or artificial (drugs of abuse) stimuli.

a pair of animals is observed and scored for naturally occurring social behaviors.

rodents prefer drinking a sucrose solution over tap water. Decreased sucrose preference is widely considered a measure of anhedonia in rodents.

the organism's unspecific response to internal or external challenges, with an adaptive value. When excessive or prolonged, it strongly contributes to mood disorders.

rodents, when hung from the tail, adopt an immobile posture interpreted as behavioral despair.

\section{References}

1. Le Merrer J, et al. Reward processing by the opioid system in the brain. Physiol Rev. 2009; 89:1379-1412. [PubMed: 19789384] 
2. Bodnar RJ. Endogenous opiates and behavior: 2010. Peptides. 2011; 32:2522-2552. [PubMed: 21983105]

3. Berrocoso E, et al. Opiates as antidepressants. Curr Pharm Des. 2009; 15:1612-1622. [PubMed: 19442177]

4. Mueller TI, et al. Recurrence after recovery from major depressive disorder during 15 years of observational follow-up. Am J Psychiatry. 1999; 156:1000-1006. [PubMed: 10401442]

5. Mathers CD, Loncar D. Projections of global mortality and burden of disease from 2002 to 2030. PLoS Med. 2006; 3:e442. [PubMed: 17132052]

6. Tenore PL. Psychotherapeutic benefits of opioid agonist therapy. J Addict Dis. 2008; 27:49-65. [PubMed: 18956529]

7. Trivedi MH, et al. Evaluation of outcomes with citalopram for depression using measurement-based care in STAR*D: implications for clinical practice. Am J Psychiatry. 2006; 163:28-40. [PubMed: 16390886]

8. Machado-Vieira R, Zarate CA Jr. Proof of concept trials in bipolar disorder and major depressive disorder: a translational perspective in the search for improved treatments. Depress Anxiety. 2011; 28:267-281. [PubMed: 21456037]

9. Gerra G, et al. Buprenorphine versus methadone for opioid dependence: predictor variables for treatment outcome. Drug Alcohol Depend. 2004; 75:37-45. [PubMed: 15225887]

10. Hegadoren KM, et al. The role of beta-endorphin in the pathophysiology of major depression. Neuropeptides. 2009; 43:341-353. [PubMed: 19647870]

11. Gaveriaux-Ruff C, Kieffer BL. Opioid receptor genes inactivated in mice: the highlights. Neuropeptides. 2002; 36:62-71. [PubMed: 12359497]

12. Nguyen AT, et al. The rewarding action of acute cocaine is reduced in beta-endorphin deficient but not in mu opioid receptor knockout mice. Eur J Pharmacol. 2012; 686:50-54. [PubMed: 22575525]

13. Nguyen AT, et al. The role of mu opioid receptors in psychomotor stimulation and conditioned place preference induced by morphine-6-glucuronide. Eur J Pharmacol. 2012; 682:86-91. [PubMed: 22374262]

14. Der-Avakian A, Markou A. The neurobiology of anhedonia and other reward-related deficits. Trends Neurosci. 2012; 35:68-77. [PubMed: 22177980]

15. Contet C, et al. Mu opioid receptor: a gateway to drug addiction. Curr Opin Neurobiol. 2004; 14:370-378. [PubMed: 15194118]

16. Filliol D, et al. Mice deficient for delta- and mu-opioid receptors exhibit opposing alterations of emotional responses. Nat Genet. 2000; 25:195-200. [PubMed: 10835636]

17. Yoo JH, et al. Altered emotional behaviors and the expression of 5-HT1A and M1 muscarinic receptors in micro-opioid receptor knockout mice. Synapse. 2004; 54:72-82. [PubMed: 15352132]

18. Pradhan AA, et al. The delta opioid receptor: an evolving target for the treatment of brain disorders. Trends Pharmacol Sci. 2011; 32:581-590. [PubMed: 21925742]

19. Chefer VI, Shippenberg TS. Augmentation of morphine-induced sensitization but reduction in morphine tolerance and reward in delta-opioid receptor knockout mice. Neuropsychopharmacology. 2009; 34:887-898. [PubMed: 18704097]

20. Le Merrer J, et al. Deletion of the delta opioid receptor gene impairs place conditioning but preserves morphine reinforcement. Biol Psychiatry. 2011; 69:700-703. [PubMed: 21168121]

21. David V, et al. Brain regional Fos expression elicited by the activation of mu- but not delta-opioid receptors of the ventral tegmental area: evidence for an implication of the ventral thalamus in opiate reward. Neuropsychopharmacology. 2008; 33:1746-1759. [PubMed: 17895918]

22. Roberts AJ, et al. Increased ethanol self-administration in delta-opioid receptor knockout mice. Alcohol Clin Exp Res. 2001; 25:1249-1256. [PubMed: 11584142]

23. Berrendero F, et al. Influence of delta-Opioid Receptors in the Behavioral Effects of Nicotine. Neuropsychopharmacology. 2012; 37:2332-2344. [PubMed: 22669166]

24. Konig M, et al. Pain responses, anxiety and aggression in mice deficient in pre-proenkephalin. Nature. 1996; 383:535-538. [PubMed: 8849726] 
25. Markou A, et al. Neurobiological similarities in depression and drug dependence: a self-medication hypothesis. Neuropsychopharmacology. 1998; 18:135-174. [PubMed: 9471114]

26. Wee S, Koob GF. The role of the dynorphin-kappa opioid system in the reinforcing effects of drugs of abuse. Psychopharmacology (Berl). 2010; 210:121-135. [PubMed: 20352414]

27. Knoll AT, Carlezon WA Jr. Dynorphin, stress, and depression. Brain Res. 2010; 1314:56-73. [PubMed: 19782055]

28. Bruchas MR, et al. The dynorphin/kappa opioid system as a modulator of stress-induced and proaddictive behaviors. Brain Res. 2010; 1314:44-55. [PubMed: 19716811]

29. Kastin AJ, et al. Enkephalin and other peptides reduce passiveness. Pharmacol Biochem Behav. 1978; 9:515-519. [PubMed: 733838]

30. Tejedor-Real P, et al. Effect of mixed (RB 38A) and selective (RB 38B) inhibitors of enkephalin degrading enzymes on a model of depression in the rat. Biol Psychiatry. 1993; 34:100-107. [PubMed: 8373929]

31. Tejedor-Real P, et al. Implication of endogenous opioid system in the learned helplessness model of depression. Pharmacol Biochem Behav. 1995; 52:145-152. [PubMed: 7501657]

32. Broom DC, et al. Nonpeptidic delta-opioid receptor agonists reduce immobility in the forced swim assay in rats. Neuropsychopharmacology. 2002; 26:744-755. [PubMed: 12007745]

33. Broom DC, et al. Convulsant activity of a non-peptidic delta-opioid receptor agonist is not required for its antidepressant-like effects in Sprague-Dawley rats. Psychopharmacology (Berl). 2002; 164:42-48. [PubMed: 12373418]

34. Javelot $\mathrm{H}$, et al. Human opiorphin is a naturally occurring antidepressant acting selectively on enkephalin-dependent delta-opioid pathways. J Physiol Pharmacol. 2010; 61:355-362. [PubMed: 20610867]

35. Jutkiewicz EM, et al. Delta-opioid agonists: differential efficacy and potency of SNC80, its 3-OH (SNC86) and 3-desoxy (SNC162) derivatives in Sprague-Dawley rats. J Pharmacol Exp Ther. 2004; 309:173-181. [PubMed: 14722329]

36. Jutkiewicz EM, et al. Differential behavioral tolerance to the delta-opioid agonist SNC80 ([(+)-4[(alphaR)-alpha-[(2S,5R)-2,5-dimethyl-4-(2-propenyl)-1-piperazinyl]-(3-me thoxyphenyl)methyl]N,N-diethylbenzamide) in Sprague-Dawley rats. J Pharmacol Exp Ther. 2005; 315:414-422. [PubMed: 16014751]

37. Jutkiewicz EM, et al. Separation of the convulsions and antidepressant-like effects produced by the delta-opioid agonist SNC80 in rats. Psychopharmacology (Berl). 2005; 182:588-596. [PubMed: 16163520]

38. Jutkiewicz EM, et al. Effects of the delta-opioid receptor agonist SNC80 on learning relative to its antidepressant-like effects in rats. Behav Pharmacol. 2003; 14:509-516. [PubMed: 14557718]

39. Jutkiewicz EM, et al. Behavioral and neurobiological effects of the enkephalinase inhibitor RB101 relative to its antidepressant effects. Eur J Pharmacol. 2006; 531:151-159. [PubMed: 16442521]

40. Naidu PS, et al. NIH 11082 produces anti-depressant-like activity in the mouse tail-suspension test through a delta-opioid receptor mechanism of action. Eur J Pharmacol. 2007; 566:132-136. [PubMed: 17459369]

41. Nieto MM, et al. Physiological control of emotion-related behaviors by endogenous enkephalins involves essentially the delta opioid receptors. Neuroscience. 2005; 135:305-313. [PubMed: 16112476]

42. Noble F, et al. Use of preproenkephalin knockout mice and selective inhibitors of enkephalinases to investigate the role of enkephalins in various behaviours. Psychopharmacology (Berl). 2008; 196:327-335. [PubMed: 17906961]

43. Saitoh A, et al. Potential anxiolytic and antidepressant-like activities of SNC80, a selective deltaopioid agonist, in behavioral models in rodents. J Pharmacol Sci. 2004; 95:374-380. [PubMed: 15272214]

44. Saitoh A, et al. The novel delta opioid receptor agonist KNT-127 produces antidepressant-like and antinociceptive effects in mice without producing convulsions. Behav Brain Res. 2011; 223:271279. [PubMed: 21565223]

45. Saitoh A, et al. Antidepressant-like effects of the delta-opioid receptor agonist SNC80 ([(+)-4[(alphaR)-alpha-[(2S,5R)-2,5-dimethyl-4-(2-propenyl)-1-piperazinyl]-(3-me thoxyphenyl)methyl]- 
N,N-diethylbenzamide) in an olfactory bulbectomized rat model. Brain Res. 2008; 1208:160-169. [PubMed: 18381208]

46. Tejedor-Real P, et al. Involvement of delta-opioid receptors in the effects induced by endogenous enkephalins on learned helplessness model. Eur J Pharmacol. 1998; 354:1-7. [PubMed: 9726624]

47. Torregrossa MM, et al. Peptidic delta opioid receptor agonists produce antidepressant-like effects in the forced swim test and regulate BDNF mRNA expression in rats. Brain Res. 2006; 1069:172181. [PubMed: 16364263]

48. Vergura R, et al. Anxiolytic- and antidepressant-like activities of H-Dmt-Tic-NH-CH(CH2$\mathrm{COOH}$ )-Bid (UFP-512), a novel selective delta opioid receptor agonist. Peptides. 2008; 29:93103. [PubMed: 18069089]

49. Yang QZ, et al. The antidepressant-like effect of human opiorphin via opioid-dependent pathways in mice. Neurosci Lett. 2011; 489:131-135. [PubMed: 21145938]

50. Berrocoso E, et al. Active behaviours produced by antidepressants and opioids in the mouse tail suspension test. Int J Neuropsychopharmacol. 2012:1-12.

51. Berrocoso E, Mico JA. Cooperative opioid and serotonergic mechanisms generate superior antidepressant-like effects in a mice model of depression. Int J Neuropsychopharmacol. 2009; 12:1033-1044. [PubMed: 19341511]

52. Besson A, et al. Effects of morphine, naloxone and their interaction in the learned-helplessness paradigm in rats. Psychopharmacology (Berl). 1996; 123:71-78. [PubMed: 8741957]

53. Rojas-Corrales MO, et al. Antidepressant-like effects of tramadol and other central analgesics with activity on monoamines reuptake, in helpless rats. Life Sci. 2002; 72:143-152. [PubMed: 12417248]

54. Zhang H, et al. Endogenous opioids upregulate brain-derived neurotrophic factor mRNA through delta- and micro-opioid receptors independent of antidepressant-like effects. Eur J Neurosci. 2006; 23:984-994. [PubMed: 16519663]

55. Beardsley PM, et al. Differential effects of the novel kappa opioid receptor antagonist, JDTic, on reinstatement of cocaine-seeking induced by footshock stressors vs cocaine primes and its antidepressant-like effects in rats. Psychopharmacology (Berl). 2005; 183:118-126. [PubMed: 16184376]

56. Mague SD, et al. Antidepressant-like effects of kappa-opioid receptor antagonists in the forced swim test in rats. J Pharmacol Exp Ther. 2003; 305:323-330. [PubMed: 12649385]

57. Shirayama Y, et al. Stress increases dynorphin immunoreactivity in limbic brain regions and dynorphin antagonism produces antidepressant-like effects. J Neurochem. 2004; 90:1258-1268. [PubMed: 15312181]

58. Krishnan V, Nestler EJ. Linking molecules to mood: new insight into the biology of depression. Am J Psychiatry. 2010; 167:1305-1320. [PubMed: 20843874]

59. Ribeiro SC, et al. Interface of physical and emotional stress regulation through the endogenous opioid system and mu-opioid receptors. Prog Neuropsychopharmacol Biol Psychiatry. 2005; 29:1264-1280. [PubMed: 16256255]

60. Nestler EJ, Carlezon WA Jr. The mesolimbic dopamine reward circuit in depression. Biol Psychiatry. 2006; 59:1151-1159. [PubMed: 16566899]

61. Svingos AL, et al. Major coexpression of kappa-opioid receptors and the dopamine transporter in nucleus accumbens axonal profiles. Synapse. 2001; 42:185-192. [PubMed: 11746715]

62. Newton SS, et al. Inhibition of cAMP response element-binding protein or dynorphin in the nucleus accumbens produces an antidepressant-like effect. J Neurosci. 2002; 22:10883-10890. [PubMed: 12486182]

63. Bertrand E, et al. Social interaction increases the extracellular levels of [Met]enkephalin in the nucleus accumbens of control but not of chronic mild stressed rats. Neuroscience. 1997; 80:17-20. [PubMed: 9252217]

64. Cordonnier L, et al. Facilitation of enkephalins-induced delta-opioid behavioral responses by chronic amisulpride treatment. Neuroscience. 2005; 135:1-10. [PubMed: 16084652]

65. Hipolito L, et al. Shell/core differences in mu- and delta-opioid receptor modulation of dopamine efflux in nucleus accumbens. Neuropharmacology. 2008; 55:183-189. [PubMed: 18582908] 
66. Devoize JL, et al. Influence of naloxone on antidepressant drug effects in the forced swimming test in mice. Psychopharmacology (Berl). 1984; 84:71-75. [PubMed: 6436893]

67. Tao R, Auerbach SB. Involvement of the dorsal raphe but not median raphe nucleus in morphineinduced increases in serotonin release in the rat forebrain. Neuroscience. 1995; 68:553-561. [PubMed: 7477965]

68. Fadda $\mathrm{P}$, et al. Dopamine and serotonin release in dorsal striatum and nucleus accumbens is differentially modulated by morphine in DBA/2J and C57BL/6J mice. Synapse. 2005; 56:29-38. [PubMed: 15700287]

69. Tao R, Auerbach SB. GABAergic and glutamatergic afferents in the dorsal raphe nucleus mediate morphine-induced increases in serotonin efflux in the rat central nervous system. J Pharmacol Exp Ther. 2002; 303:704-710. [PubMed: 12388654]

70. Jolas T, et al. Chronic morphine increases GABA tone on serotonergic neurons of the dorsal raphe nucleus: association with an up-regulation of the cyclic AMP pathway. Neuroscience. 2000; 95:433-443. [PubMed: 10658623]

71. Anraku T, et al. Withdrawal from chronic morphine administration causes prolonged enhancement of immobility in rat forced swimming test. Psychopharmacology (Berl). 2001; 157:217-220. [PubMed: 11594449]

72. Molina VA, et al. Chronic variable stress or chronic morphine facilitates immobility in a forced swim test: reversal by naloxone. Psychopharmacology (Berl). 1994; 114:433-440. [PubMed: 7855201]

73. Grasing K, Ghosh S. Selegiline prevents long-term changes in dopamine efflux and stress immobility during the second and third weeks of abstinence following opiate withdrawal. Neuropharmacology. 1998; 37:1007-1017. [PubMed: 9833630]

74. Hodgson SR, et al. Different affective response to opioid withdrawal in adolescent and adult mice. Life Sci. 2009; 84:52-60. [PubMed: 19032959]

75. Goeldner C, et al. Impaired emotional-like behavior and serotonergic function during protracted abstinence from chronic morphine. Biol Psychiatry. 2011; 69:236-244. [PubMed: 20947067]

76. Lutz PE, et al. Sequential and opposing alterations of 5-HT(1A) receptor function during withdrawal from chronic morphine. Eur Neuropsychopharmacol. 2011; 21:835-840. [PubMed: 21402471]

77. Rainer Q, et al. Functional status of somatodendritic serotonin 1A autoreceptor after long-term treatment with fluoxetine in a mouse model of anxiety/depression based on repeated corticosterone administration. Mol Pharmacol. 2012; 81:106-112. [PubMed: 22031471]

78. Zhao ZQ, et al. Central serotonergic neurons are differentially required for opioid analgesia but not for morphine tolerance or morphine reward. Proc Natl Acad Sci U S A. 2007; 104:14519-14524. [PubMed: 17724336]

79. Tao R, Auerbach SB. Opioid receptor subtypes differentially modulate serotonin efflux in the rat central nervous system. J Pharmacol Exp Ther. 2002; 303:549-556. [PubMed: 12388635]

80. Land BB, et al. Activation of the kappa opioid receptor in the dorsal raphe nucleus mediates the aversive effects of stress and reinstates drug seeking. Proc Natl Acad Sci U S A. 2009; 106:1916819173. [PubMed: 19864633]

81. Bruchas MR, et al. Selective p38alpha MAPK Deletion in Serotonergic Neurons Produces Stress Resilience in Models of Depression and Addiction. Neuron. 2011; 71:498-511. [PubMed: 21835346]

82. Rossetti ZL, et al. Extraneuronal noradrenaline in the prefrontal cortex of morphine-dependent rats: tolerance and withdrawal mechanisms. Brain Res. 1993; 609:316-320. [PubMed: 8508313]

83. Delfs JM, et al. Noradrenaline in the ventral forebrain is critical for opiate withdrawal-induced aversion. Nature. 2000; 403:430-434. [PubMed: 10667795]

84. Harris GC, Aston-Jones G. Activation in extended amygdala corresponds to altered hedonic processing during protracted morphine withdrawal. Behav Brain Res. 2007; 176:251-258. [PubMed: 17123639]

85. Hanson ND, et al. Depression, antidepressants, and neurogenesis: a critical reappraisal. Neuropsychopharmacology. 2011; 36:2589-2602. [PubMed: 21937982] 
86. Snyder JS, et al. Adult hippocampal neurogenesis buffers stress responses and depressive behaviour. Nature. 2011; 476:458-461. [PubMed: 21814201]

87. Robinson TE, et al. Widespread but regionally specific effects of experimenter-versus selfadministered morphine on dendritic spines in the nucleus accumbens, hippocampus, and neocortex of adult rats. Synapse. 2002; 46:271-279. [PubMed: 12373743]

88. Eisch AJ, Harburg GC. Opiates, psychostimulants, and adult hippocampal neurogenesis: Insights for addiction and stem cell biology. Hippocampus. 2006; 16:271-286. [PubMed: 16411230]

89. Harburg GC, et al. Knockout of the mu opioid receptor enhances the survival of adult-generated hippocampal granule cell neurons. Neuroscience. 2007; 144:77-87. [PubMed: 17055658]

90. Cominski TP, et al. Loss of the mu opioid receptor on different genetic backgrounds leads to increased bromodeoxyuridine labeling in the dentate gyrus only after repeated injection. Neuroscience. 2012; 206:49-59. [PubMed: 22280973]

91. Dranovsky A, et al. Experience dictates stem cell fate in the adult hippocampus. Neuron. 2011; 70:908-923. [PubMed: 21658584]

92. Song P, Zhao ZQ. The involvement of glial cells in the development of morphine tolerance. Neurosci Res. 2001; 39:281-286. [PubMed: 11248367]

93. Persson AI, et al. Mu- and delta-opioid receptor antagonists decrease proliferation and increase neurogenesis in cultures of rat adult hippocampal progenitors. Eur J Neurosci. 2003; 17:11591172. [PubMed: 12670304]

94. Castren E, Rantamaki T. The role of BDNF and its receptors in depression and antidepressant drug action: Reactivation of developmental plasticity. Dev Neurobiol. 2010; 70:289-297. [PubMed: 20186711]

95. Torregrossa MM, et al. The delta-opioid receptor agonist (+)BW373U86 regulates BDNF mRNA expression in rats. Neuropsychopharmacology. 2004; 29:649-659. [PubMed: 14647482]

96. Zhang H, et al. Central kappa-opioid receptor-mediated antidepressant-like effects of norBinaltorphimine: behavioral and BDNF mRNA expression studies. Eur J Pharmacol. 2007; 570:89-96. [PubMed: 17601558]

97. Ansorge MS, et al. Neurodevelopmental origins of depressive disorders. Curr Opin Pharmacol. 2007; 7:8-17. [PubMed: 17188022]

98. Bale TL, et al. Early life programming and neurodevelopmental disorders. Biol Psychiatry. 2010; 68:314-319. [PubMed: 20674602]

99. Traudt CM, et al. Postnatal morphine administration alters hippocampal development in rats. J Neurosci Res. 2012; 90:307-314. [PubMed: 21971612]

100. Klausz B, et al. Changes in adaptability following perinatal morphine exposure in juvenile and adult rats. Eur J Pharmacol. 2011; 654:166-172. [PubMed: 21147096]

101. de Cubas MM, Field T. Children of methadone-dependent women: developmental outcomes. Am J Orthopsychiatry. 1993; 63:266-276. [PubMed: 7683453]

102. Ornoy A, et al. The developmental outcome of children born to heroin-dependent mothers, raised at home or adopted. Child Abuse Negl. 1996; 20:385-396. [PubMed: 8735375]

103. Meyer-Lindenberg A, Tost H. Neural mechanisms of social risk for psychiatric disorders. Nat Neurosci. 2012; 15:663-668. [PubMed: 22504349]

104. Stein DJ, et al. Opioids: from physical pain to the pain of social isolation. CNS Spectr. 2007; 12:669-670. [PubMed: 17805212]

105. Eisenberger NI. The pain of social disconnection: examining the shared neural underpinnings of physical and social pain. Nat Rev Neurosci. 2012; 13:421-434. [PubMed: 22551663]

106. Panksepp J. Neuroscience. Feeling the pain of social loss. Science. 2003; 302:237-239. [PubMed: 14551424]

107. Kennedy BC, et al. Social influences on morphine-conditioned place preference in adolescent BALB/cJ and C57BL/6J mice. Psychopharmacology (Berl). 2012; 219:923-932. [PubMed: 21837434]

108. Komatsu H, et al. Decreased response to social defeat stress in mu-opioid-receptor knockout mice. Pharmacol Biochem Behav. 2011; 99:676-682. [PubMed: 21703297] 
109. Mague SD, Blendy JA. OPRM1 SNP (A118G): involvement in disease development, treatment response, and animal models. Drug Alcohol Depend. 2010; 108:172-182. [PubMed: 20074870]

110. Troisi A, et al. Social hedonic capacity is associated with the A118G polymorphism of the muopioid receptor gene (OPRM1) in adult healthy volunteers and psychiatric patients. Soc Neurosci. 2011; 6:88-97. [PubMed: 20486014]

111. Way BM, et al. Variation in the mu-opioid receptor gene (OPRM1) is associated with dispositional and neural sensitivity to social rejection. Proc Natl Acad Sci U S A. 2009; 106:15079-15084. [PubMed: 19706472]

112. McLaughlin JP, et al. Social defeat stress-induced behavioral responses are mediated by the endogenous kappa opioid system. Neuropsychopharmacology. 2006; 31:1241-1248. [PubMed: 16123746]

113. Resendez SL, et al. kappa-Opioid Receptors within the Nucleus Accumbens Shell Mediate Pair Bond Maintenance. J Neurosci. 2012; 32:6771-6784. [PubMed: 22593047]

114. Niesink RJ, et al. Social behavior of juvenile rats after in utero exposure to morphine: dose-timeeffect relationship. Neuropharmacology. 1999; 38:1207-1223. [PubMed: 10462133]

115. Hol T, et al. Prenatal exposure to morphine affects juvenile play behavior and adult social behavior in rats. Pharmacol Biochem Behav. 1996; 55:615-618. [PubMed: 8981592]

116. Bowlby J. Attachment and loss: retrospect and prospect. Am J Orthopsychiatry. 1982; 52:664678. [PubMed: 7148988]

117. Moles A, et al. Deficit in attachment behavior in mice lacking the mu-opioid receptor gene. Science. 2004; 304:1983-1986. [PubMed: 15218152]

118. Kalin NH, Shelton SE. Defensive behaviors in infant rhesus monkeys: environmental cues and neurochemical regulation. Science. 1989; 243:1718-1721. [PubMed: 2564702]

119. Barr CS, et al. Variation at the mu-opioid receptor gene (OPRM1) influences attachment behavior in infant primates. Proc Natl Acad Sci U S A. 2008; 105:5277-5281. [PubMed: 18378897]

120. Copeland WE, et al. Child mu-opioid receptor gene variant influences parent-child relations. Neuropsychopharmacology. 2011; 36:1165-1170. [PubMed: 21326192]

121. Kalinichev M, et al. Early neonatal experience of Long-Evans rats results in long-lasting changes in morphine tolerance and dependence. Psychopharmacology (Berl). 2001; 157:305-312. [PubMed: 11605087]

122. Kalinichev M, et al. Repeated neonatal maternal separation alters morphine-induced antinociception in male rats. Brain Res Bull. 2001; 54:649-654. [PubMed: 11403991]

123. Weaver SA, et al. Maternal separation leads to persistent reductions in pain sensitivity in female rats. J Pain. 2007; 8:962-969. [PubMed: 17686657]

124. Liu D, et al. Maternal care, hippocampal glucocorticoid receptors, and hypothalamic-pituitaryadrenal responses to stress. Science. 1997; 277:1659-1662. [PubMed: 9287218]

125. Lewis JM. For better or worse: interpersonal relationships and individual outcome. Am J Psychiatry. 1998; 155:582-589. [PubMed: 9585706]

126. Ladd GW. Peer relationships and social competence during early and middle childhood. Annu Rev Psychol. 1999; 50:333-359. [PubMed: 10074682]

127. Panksepp JB, Lahvis GP. Social reward among juvenile mice. Genes Brain Behav. 2007; 6:661671. [PubMed: 17212648]

128. Trezza V, et al. The pleasures of play: pharmacological insights into social reward mechanisms. Trends Pharmacol Sci. 2010; 31:463-469. [PubMed: 20684996]

129. Van den Berg CL, et al. Morphine treatment during juvenile isolation increases social activity and opioid peptides release in the adult rat. Brain Res. 1999; 830:16-23. [PubMed: 10350555]

130. Vanderschuren LJ, et al. Mu- and kappa-opioid receptor-mediated opioid effects on social play in juvenile rats. Eur J Pharmacol. 1995; 276:257-266. [PubMed: 7601211]

131. Kessler RC. The epidemiology of dual diagnosis. Biol Psychiatry. 2004; 56:730-737. [PubMed: 15556117]

132. Paterson NE, Markou A. Animal models and treatments for addiction and depression comorbidity. Neurotox Res. 2007; 11:1-32. [PubMed: 17449445] 
133. Nunes EV, et al. Treatment of depression in patients with opiate dependence. Biol Psychiatry. 2004; 56:793-802. [PubMed: 15556125]

134. Lutfy K, Cowan A. Buprenorphine: a unique drug with complex pharmacology. Curr Neuropharmacol. 2004; 2:395-402. [PubMed: 18997874]

135. Escriba PV, et al. Increased mRNA expression of alpha2A-adrenoceptors, serotonin receptors and mu-opioid receptors in the brains of suicide victims. Neuropsychopharmacology. 2004; 29:15121521. [PubMed: 15199368]

136. Gabilondo AM, et al. Increased density of mu-opioid receptors in the postmortem brain of suicide victims. Brain Res. 1995; 682:245-250. [PubMed: 7552322]

137. Gross-Isseroff R, et al. Regionally selective increases in mu opioid receptor density in the brains of suicide victims. Brain Res. 1990; 530:312-316. [PubMed: 2176118]

138. Zubieta JK, et al. Regulation of human affective responses by anterior cingulate and limbic muopioid neurotransmission. Arch Gen Psychiatry. 2003; 60:1145-1153. [PubMed: 14609890]

139. Kennedy SE, et al. Dysregulation of endogenous opioid emotion regulation circuitry in major depression in women. Arch Gen Psychiatry. 2006; 63:1199-1208. [PubMed: 17088500]

140. Shippenberg TS, et al. Targeting endogenous mu- and delta-opioid receptor systems for the treatment of drug addiction. CNS Neurol Disord Drug Targets. 2008; 7:442-453. [PubMed: 19128202]

141. Tejeda HA, et al. The dynorphin/kappa-opioid receptor system and its role in psychiatric disorders. Cell Mol Life Sci. 2012; 69:857-896. [PubMed: 22002579]

142. Manglik A, et al. Crystal structure of the micro-opioid receptor bound to a morphinan antagonist. Nature. 2012; 485:321-326. [PubMed: 22437502]

143. Granier S, et al. Structure of the delta-opioid receptor bound to naltrindole. Nature. 2012; 485:400-404. [PubMed: 22596164]

144. Wu H, et al. Structure of the human kappa-opioid receptor in complex with JDTic. Nature. 2012; 485:327-332. [PubMed: 22437504]

145. Haga K, et al. Structure of the human M2 muscarinic acetylcholine receptor bound to an antagonist. Nature. 2012; 482:547-551. [PubMed: 22278061]

146. He L, et al. Regulation of opioid receptor trafficking and morphine tolerance by receptor oligomerization. Cell. 2002; 108:271-282. [PubMed: 11832216]

147. Shukla AK, et al. Emerging paradigms of beta-arrestin-dependent seven transmembrane receptor signaling. Trends Biochem Sci. 2011; 36:457-469. [PubMed: 21764321]

148. Pradhan AA, et al. Ligand-Directed Signaling Within the Opioid Receptor Family. Br J Pharmacol doi:. 2012 10.1111/j.1476-5381.2012.02075.x.

149. Tassin JP. Uncoupling between noradrenergic and serotonergic neurons as a molecular basis of stable changes in behavior induced by repeated drugs of abuse. Biochem Pharmacol. 2008; 75:85-97. [PubMed: 17686465]

150. Sharp BM. Multiple opioid receptors on immune cells modulate intracellular signaling. Brain Behav Immun. 2006; 20:9-14. [PubMed: 16364815]

151. Sery O, et al. A118G polymorphism of OPRM1 gene is associated with schizophrenia. J Mol Neurosci. 2010; 41:219-222. [PubMed: 20112002]

152. Prossin AR, et al. Dysregulation of regional endogenous opioid function in borderline personality disorder. Am J Psychiatry. 2010; 167:925-933. [PubMed: 20439388]

153. Olmstead MC, et al. Mu and delta opioid receptors oppositely regulate motor impulsivity in the signaled nose poke task. PLoS One. 2009; 4:e4410. [PubMed: 19198656] 
Box 1

\section{Outstanding questions}

- Opioid receptors: molecular aspects and biased agonism

The recent and long-awaited high resolution crystal structures of MOR [142], DOR [143] and KOR [144] represent a breakthrough. In their ligand-bound inactive form, these receptors share a conserved wide-open binding pocket [143] contrasting with buried pockets of GPCRs crystallized so far (eg. [145]). MORs form intimate oligomeric pairs within the crystal [142], supporting the view that opioid receptors may function as oligomers [146]. Demonstrating their physiological relevance currently represents an important and ongoing experimental challenge.

Opioid receptors are coupled to $\mathrm{Ga}_{\mathrm{i} / \mathrm{o}}$ proteins and their activation overall inhibits neuronal activity. Opioid receptors also stimulate $\mathrm{G}$ protein-independent signaling pathways, notably via $\beta$-arrestins [147]. A main goal in the GPCR field is the identification of signaling pathways operating in vivo to control specific behavioral responses. Such biased agonism (now emerging for all three opioid receptors [148]), in combination with structure-based approaches, will likely aid in the development of future antidepressants devoid of adverse effects (ie. dependence liability for MOR agonists, convulsive seizures for DOR agonists, and hyperalgesic effects of KOR antagonists).

\section{- Dynamics of opioid-driven adaptations in monoaminergic systems}

A major challenge in the future will be to unravel dynamic adaptations of the endogenous opioid system, as mood disruption emerges and evolves. This issue is of significant clinical relevance, as many brain disorders implicating the opioid system are defined as chronic relapsing diseases (eg. addiction, MDD, chronic pain). In particular, opioid receptors exert multiple controls over the main monoaminergic systems in rodents. Addiction research suggests that repeated exposure to drugs of abuse disrupt mutual inhibitory feedback mechanisms between monoaminergic nuclei, inducing long-term adaptations at the behavioral level [149]. Whether such mechanisms also impair mood, possibly through opioid receptors, is an intriguing hypothesis.

\section{- Opioids and novel aspects in mood research}

Future studies will also address the potential implication of opioid receptors in newly identified mechanisms of depression, revealed by fast-acting antidepressant effects of NMDA receptor antagonists (eg. ketamine) or 5-HT4 receptor agonists. Also, considering the immune theory of depression, the well-established immunomodulatory function of opioid receptors [150] may have implications in mood control.

\section{- Opioid and mood beyond MDD}

Opioid receptors may contribute to mood disruption in psychiatric disorders other than MDD. Clinical data implicate the opioid system in schizophrenia [151] and borderline personality disorder [152], two conditions involving dysregulation of emotional and reward processes. At present, however, animal models of bipolar or borderline personality disorders, or affective dimensions of schizophrenia, are poorly characterized.

In addition, recent studies revealed enhanced motor impulsivity in MOR KO mice [153]. The latter finding opens the way to consider mu receptors in a variety of impulse control disorders: antisocial and borderline personality disorders, attention deficit hyperactivity disorder, eating disorders and obsessive-compulsive disorder. 
Finally, the crucial role of the opioid system in parental attachment [111, 117, 119], social behaviors [103] and social pain [105] may have implications for the understanding of autism spectrum disorders which have been linked to deficits in social motivation. 


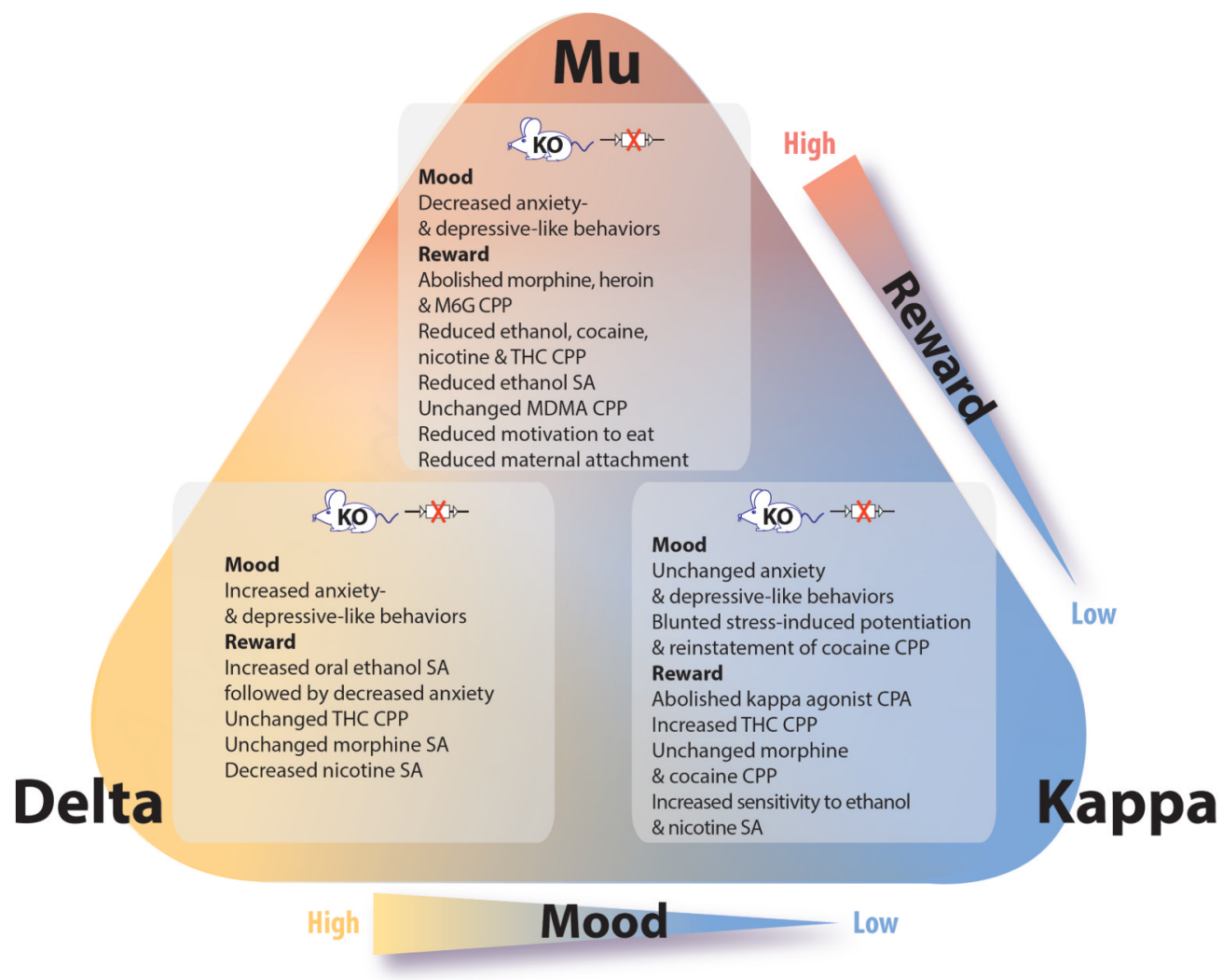

Figure 1. Opioid receptor knockout (KO) mice phenotypes in models of addiction and mood disorders

Behavioral modifications are summarized for each receptor constitutive KO mouse line. Important conclusions from these data are the following: mu opioid receptors (MORs) are key mediators of both natural and artificial rewards $[12,13,15]$, and may show prodepressant activity $[16,17]$ although this is not supported by the pharmacology. Kappa opioid receptors (KORs) mediatedysphoria, particularly under stressful conditions where the dynorphin/KOR activity is higher [26-28]. Delta opioid receptors (DORs) decrease levels of anxiety and reduce depressive-like behaviors [16], however, its role in reward remains debated [18-23]. Exhaustive reviews are available on the role of MORs in reward processes [1], the emerging roles of DORs in brain disorders [18], the potential of MORs and DORs as targets to treat addiction [140], and the role of KORs in stress-induced and pro-addictive behaviors or more general psychiatric disorders [141]. Abbreviations: CPA conditioned place aversion; CPP, conditioned place preference; MDMA, 3,4-methylenedioxy- $N$ methylamphetamine; M6G, morphine-6-glucoronide, the active metabolite of morphine; SA, self-administration; THC, delta-9-tetrahydrocannabinol. 

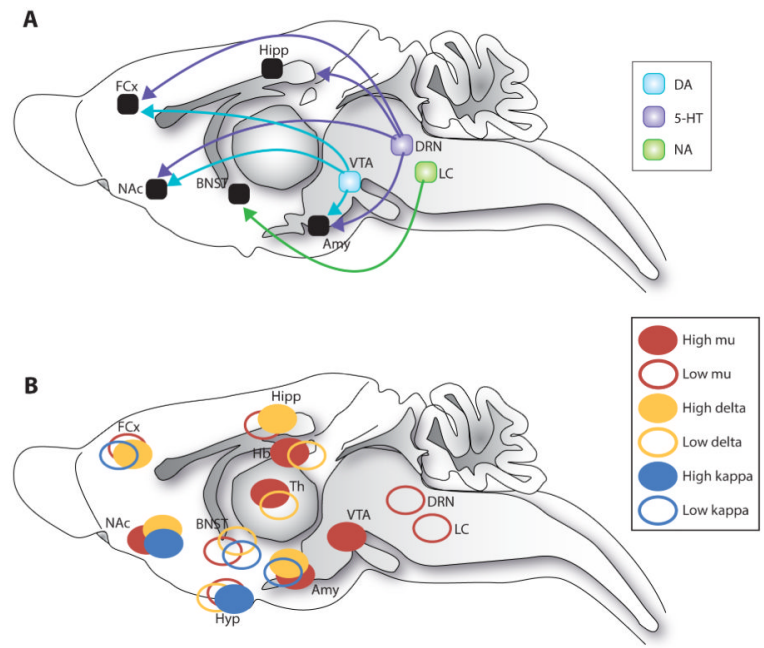

C

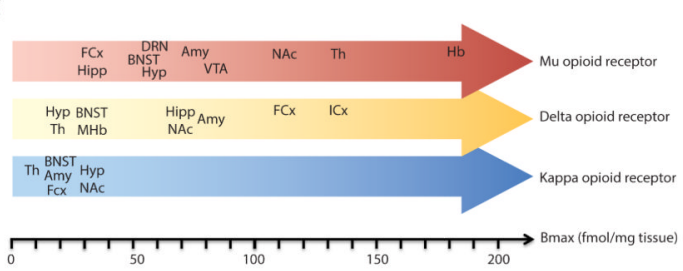

Figure 2. Anatomical distribution of opioid receptors throughout neural circuits of mood in the rodent brain

(A) Schematic representation of main monoaminergic nuclei and projections forming neural circuitry of reward processing and emotional responses, as discussed in the present review. Dysfunction in the mesolimbic DA circuit [60] is mostly associated with anhedonia and reduced motivation at the level of ventral tegmental area (VTA) and nucleus accumbens (NAc). 5-HT and NA neurons originating from the dorsal raphe nucleus (DRN) and the locus coeruleus (LC) respectively, project widely throughout the brain with a main implication of hippocampal (Hipp), prefrontal cortex (PFC), nucleus accumbens (NAc) and bed nucleus of the stria terminalis (BNST) projection areas involved in mood disorders, while the amygdala (Amy) is a main brain region involved in emotional dysfunction [58]. (B) $\mathrm{Mu}$, delta and kappa opioid receptors (MORs, DORs and KORs, respectively) show overlapping but distinct anatomical distributions in neural circuits of mood. (C) Absolute protein expression levels of MORs, DORs and KORs across relevant brain structures are shown (from [1]). Of note is that anatomical studies in humans have mainly addressed cortical networks and comparing human with rodent data is currently difficult. For example, MORs in the anterior insular and dorsal anterior cingulate cortex has been implicated in social rejection in humans [111], yet their role in animal models of social separation or stress remains unexplored. Also, human imaging studies reveal a role for MORs in the thalamus (Th) in MDD [139], a receptor population ignored so far in animal models. Abbreviations: Hb, habenula; Hyp, hypothalamus; ICx, insular cortex; MHb, medial habenula; Th, thalamus 


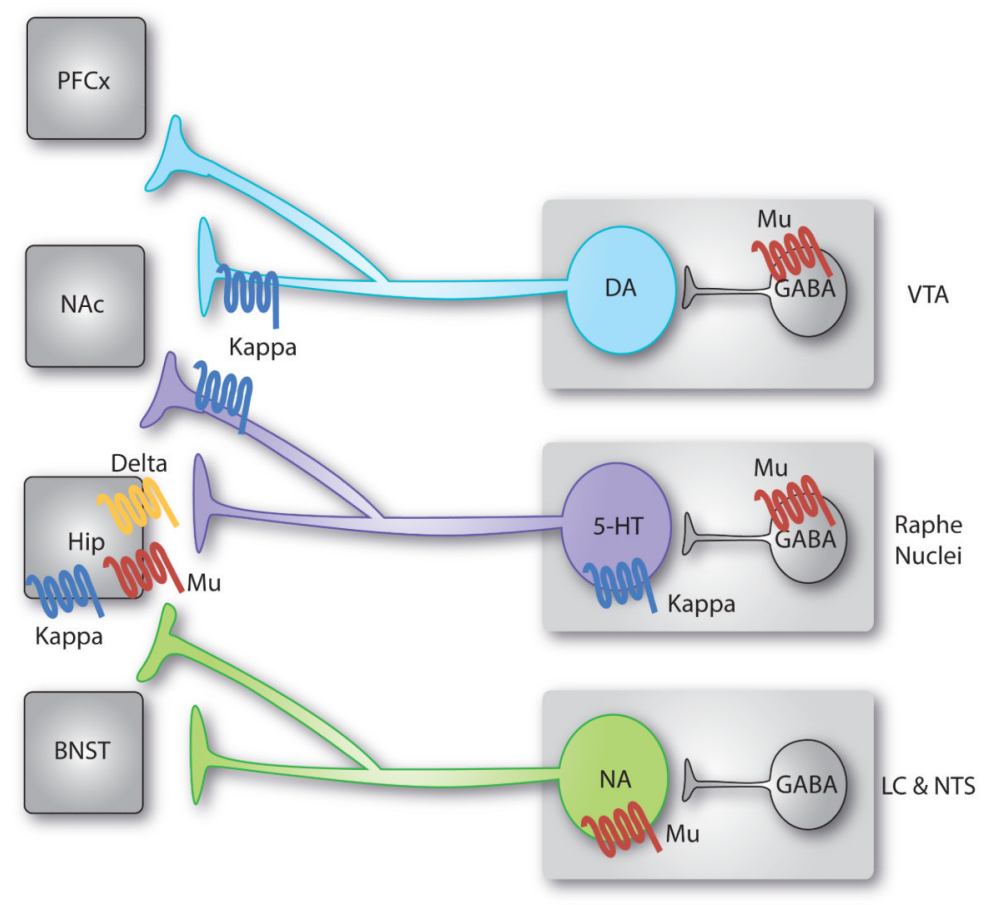

Figure 3. Functional interactions between opioid receptors and monoaminergic systems relevant to mood control

Monoaminergic neurons synthesizing dopamine (DA), serotonin (5-HT) and nordrenaline (NA) originate in the brainstem and send axonal projections throughout the whole brain. These neurons are regulated by opioid receptors at multiple sites. Represented here are main receptor pools, where functional effects have been documented or proposed in the context of mood-related behaviors (see text for details). Other receptor populations may also contribute. In summary, activation of mu opioid receptors (MORs) expressed in the dorsal raphe nucleus (DRN) and ventral tegmental area (VTA) by local GABAergic interneurons disinhibit 5-HT [67-70] and DA [1] neurons. On the contrary, noradrenergic neurons are directly inhibited by MORs [83]. Chronic morphine treatment targets MORs in all these regions. Acute withdrawal from chronic morphine produces conditioned place aversion (CPA), which relies on increased activity of noradrenergic neurons targeting the bed nucleus of stria terminalis (BNST) [83]. Prolonged withdrawal from chronic morphine, or abstinence, leads to 5-HT dysfunction and progressive depressive-like behaviours [75, 76]. Kappa opioid receptors (KORs) expressed presynaptically in the nucleus accumbens (NAc) by 5-HT neurons are sufficient for KOR-induced CPA [80]. In addition, stress potentiates the activity of the dynorphin/KOR system, which targets both (i) DA neurons (and possibly 5-HT neurons) in the NAc to produce depressive-like behaviours [27], and (ii) 5-HT neurons in the DRN to mediate acute social avoidance [81]. Finally, evidence suggests that additional receptor populations are likely to be implicated in mood regulation: all 3 opioid receptors modulate BDNF activity and neurogenesis in the hippocampus (Hipp) [88], and KORs selectively control DA neurons projecting to the prefrontal cortex (PFC) [27]. 


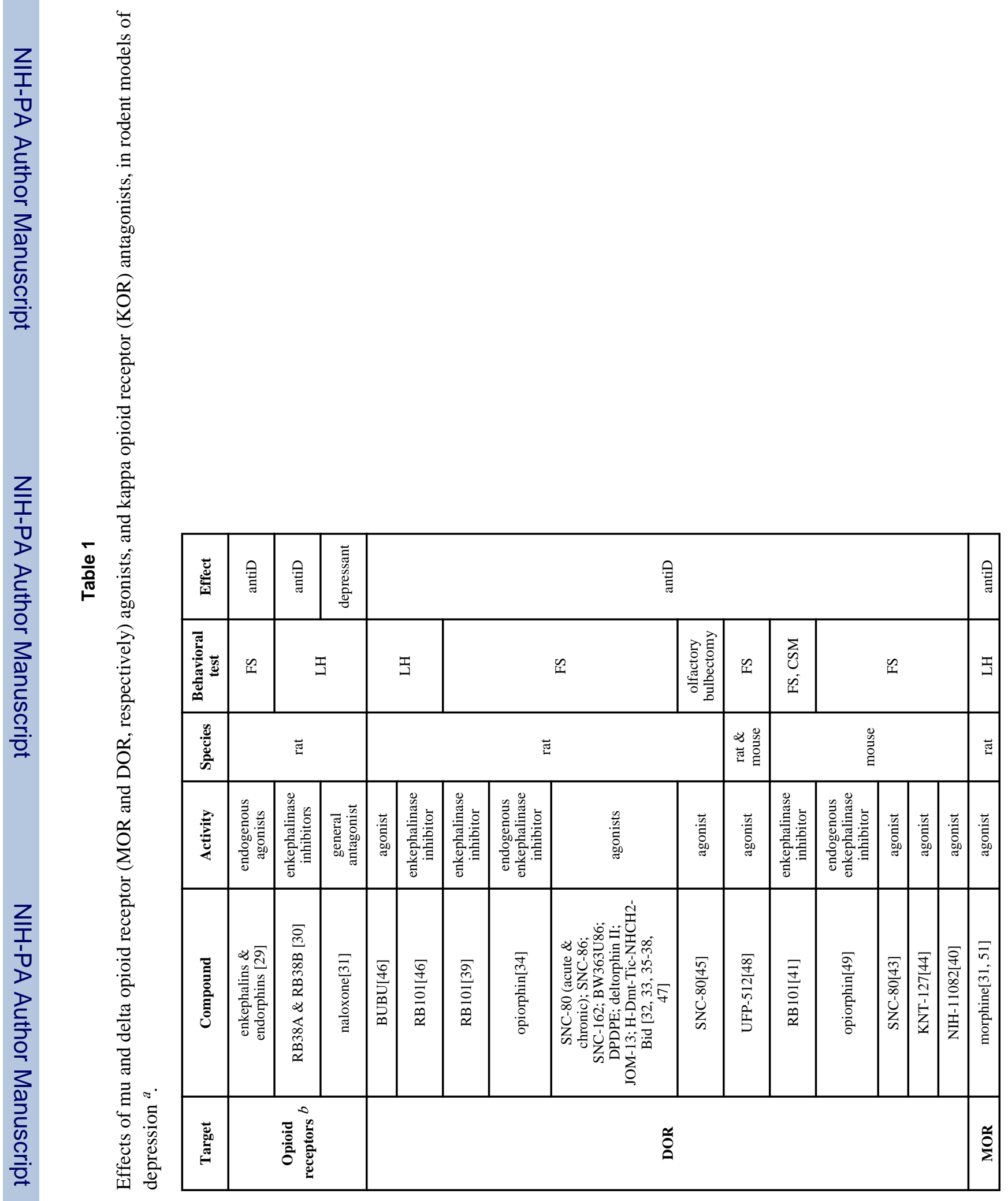




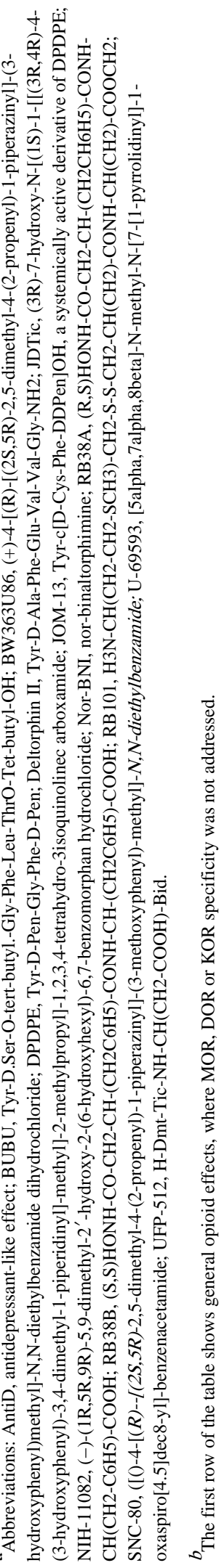

